\title{
Article \\ Involvement of Hemopexin in the Pathogenesis of Proteinuria in Children with Idiopathic Nephrotic Syndrome
}

\author{
Agnieszka Pukajło-Marczyk * and Danuta Zwolińska \\ Department of Pediatric Nephrology, Wroclaw Medical University, Borowska 213, 50-556 Wroclaw, Poland; \\ danuta.zwolinska@umed.wroc.pl \\ * Correspondence: pukajlo-marczyk@umed.wroc.pl
}

check for

updates

Citation: Pukajło-Marczyk, A.; Zwolińska, D. Involvement of Hemopexin in the Pathogenesis of Proteinuria in Children with Idiopathic Nephrotic Syndrome. J. Clin. Med. 2021, 10, 3160. https:// doi.org/10.3390/jcm10143160

Academic Editors:

Katarzyna Taranta-Janusz and Jonathan Barratt

Received: 30 May 2021

Accepted: 15 July 2021

Published: 17 July 2021

Publisher's Note: MDPI stays neutral with regard to jurisdictional claims in published maps and institutional affiliations.

Copyright: (c) 2021 by the authors. Licensee MDPI, Basel, Switzerland. This article is an open access article distributed under the terms and conditions of the Creative Commons Attribution (CC BY) license (https:// creativecommons.org/licenses/by/ $4.0 /)$.

\begin{abstract}
Hemopexin (Hpx) is considered a factor in the pathogenesis of idiopathic nephrotic syndrome (INS). The aim of the study was to evaluate the serum and urine values of Hpx (sHpx and $\mathrm{uHpx}$ ) in children with INS, analyze the role of Hpx, and assess its usefulness as a marker of the disease course. 51 children with INS and 18 age-matched controls were examined. Patients were divided into subgroups depending on the number of relapses (group IA-the first episode of INS, group IB-with relapses) and according to method of treatment (group IIA treated with gluco-corticosteroids (GCS), group IIB treated with GCS and other immunosuppressants). Hpx concentrations were determined by enzyme-linked immunosorbent assay (ELISA). sHpx and uHpx values in relapse were elevated in the whole INS group versus controls $(p<0.000)$. In remission their levels decreased, but still remained higher than in the control group $(p<0.000)$. In group IB uHpx levels were increased during remission as compared to group IA $(p<0.006)$. No significant impact of immuno-suppressants on sHpx was observed, but uHpx excretion in group IIA was higher in relapse $(p<0.026)$ and lower in remission $(p<0.0017)$ as compared to group IIB. The results suggest the role of Hpx in the pathogenesis of INS. Hpx may be a useful indicator for continuation of treatment, but it requires confirmation by further controlled studies.
\end{abstract}

Keywords: hemopexin; nephrotic syndrome; children

\section{Introduction}

Various factors can damage the glomerular filtration barrier and trigger nephrotic proteinuria. The child's age at the time of the manifestation of symptoms allows the diagnostic process to be directed in search of the disease etiology. Up to 1 year of age, nephrotic syndrome is the result of mutations in genes encoding podocyte proteins or may be associated with congenital infections such as syphilis or toxoplasmosis [1]. Podocyte function may also be impaired in the course of lysosomal diseases, which should be considered in the diagnostic procedure, especially in the case of the development of nephropathy in young children [2]. In older children, nephrotic syndrome may develop in the course of autoimmune inflammatory diseases, such as lupus erythematosus, acute poststreptococcal glomerulonephritis, IgAN (IgA Nephropathy) or IgAVN (Immunoglobulin (Ig)A vasculitis nephritis) [3-5].

Idiopathic nephrotic syndrome (INS) is the most common form of podocytopathy in children. It accounts for over $90 \%$ of cases in the group between 1 and 10 years of age and about $50 \%$ in the group of children over 10 years of age. The incidence is estimated at about 16 cases per 100,000 of the pediatric population and at two-seven new cases per 100,000 children under 15 years of age. The diagnostic criteria are massive proteinuria above $50 \mathrm{mg} / \mathrm{kg} /$ day, hypoalbuminemia $(<2.5 \mathrm{~g} / \mathrm{L})$ and edema [6,7]. These symptoms are accompanied by hyperlipidemia. Minimal change disease (MCD) is the most common morphologic feature of this syndrome (approximately $85 \%$ of cases), followed by focal segmental glomerulosclerosis (FSGS) and mesangial proliferative glomerulonephritis (MPGN). In each of these forms, there is the effacement of podocyte foot processes and structural 
disorganization of the glomerular filtration barrier (GFB). While the vast majority of patients $(80-90 \%)$ respond well to gluco-corticosteroids (GCS), primary steroid resistance is observed in approximately $10 \%$, mainly in FSGS patients, with a poorer prognosis for renal survival $[8,9]$. The course of INS is characterized by periods of remissions and relapses, usually induced by upper respiratory tract infections.

The pathogenesis of nephrotic proteinuria in MCD is complex and still not fully elucidated, as evidenced by the emergence of new hypotheses [10]. The earliest, from the 1970s, suggested that circulating protein permeability factors released by dysfunctional T lymphocytes were responsible for the development of proteinuria in MCD [11]. Various candidate cytokines, whose elevated levels were observed in the serum and urine of children with recurrent MCD, were considered. Out of these, IL-8 and IL-13 were found to be the most likely pathogenic factors. However, it should be emphasized that the reported results of many studies were inconclusive [12-14].

A more recent theory, the "two-hit" theory, posits that the process of podocyte damage is more complex and partially combines the earlier hypotheses $[15,16]$. The first hit is the stimulation of podocytes by T-linked cytokines, bacterial or viral fragments, allergens or other factors, resulting in increased expression of CD80 (B7-1). Induction of CD80 leads to podocyte damage and increased permeability to proteins. If normal podocyte autoregulation is maintained, T-regulatory cells (T-reg) prevent this phenomenon, with the involvement of the CTLA-4 molecule, IL-10 and TGF-beta [17]. If these mechanisms fail, permanent overexpression of CD80 occurs, resulting in the full-blown MCD. In contrast, achieving remission after rituximab, a monoclonal antibody directed against CD-20, points to the involvement of B lymphocytes in INS development [18]. The role of circulating factors in the pathogenesis of proteinuria in INS remains of interest [19-23].

Hemopexin (Hpx) is a circulating plasma $\beta-1$ glycoprotein with a molecular weight of $60 \mathrm{kDa}$, encoded by a gene located on chromosome 11 (pp. 15.4-15.5) [24-26]. It is synthesized mainly in hepatocytes as a single polypeptide chain. Its spatial structure is determined by two disulfide bonds connecting structurally related domains (C- and $\mathrm{N}$-terminal) and binding the heme moiety [27]. Hpx plays a role in iron homeostasis by binding heme released into serum and then transporting it to the liver where it is disintegrated $[28,29]$. The half-life of Hpx in serum is 7 days. Low concentrations may be a marker of hemolysis severity, whereas its absence may indicate either insufficient synthesis in the course of chronic liver diseases or severe malnutrition. Under physiological conditions, the mean urinary Hpx concentration is $2 \mathrm{mg} / \mathrm{L}$, and its increase has been observed in diabetes, when glomerular proteinuria develops $[30,31]$. Increased levels of Hpx have also been shown in inflammatory psychiatric disorders, cancer, and neuromuscular diseases [32-34].

Hpx has serine protease activity. It exhibits anti- and pro-inflammatory effects and inhibits multinuclear granulocyte necrosis and cell adhesion [23]. In recent years, the effect of Hpx as a circulating factor on GFB permeability and the development of proteinuria has been postulated.

\section{Aim of the Study}

The aim of the study was to evaluate the serum and urine Hpx concentration in children with INS as a pathogenic factor and to determine its usefulness as a predictor of disease severity.

\section{Material and Methods}

The study group consisted of 69 children, including 51 children with INS (INS group), 19 girls and 32 boys, ranging in age from $1.25-18$ years (mean age $8.86 \pm 5.2$ years). The diagnosis of INS was established according to ISKDC criteria [35]. Steroid sensitivity was defined as the achievement of remission during the first 4 weeks of GCS treatment, and steroid dependence as the occurrence of at least two relapses during the period of steroid dose reduction or within 2 weeks after GCS cessation. Remission was defined as the absence of protein in urine for at least 3 consecutive days. 
The group of patients with INS was further divided into subgroups: group IA consisted of 20 children ( 5 girls, 15 boys; mean age $5.90 \pm 4.91$ years), with the first occurrence of INS, and group IB consisted of 31 children (14 girls, 17 boys; mean age $10.31 \pm 4.81$ years), with relapses (from 2-16 relapses, mean 11.8).

Additionally, in order to assess the severity of the course of INS, a second division was made according to the applied treatment. Group IIA included 26 children ( 7 girls, 19 boys; mean age $5.59 \pm 4.04$ years), treated only with GCS. In relapse standard doses of prednisone $(2 \mathrm{mg} / \mathrm{kg} /$ day) were used, and in individual cases pulses of methylprednisolone $0.5 \mathrm{~g} /$ dose were also required. Group II B included 22 children ( 9 girls, 13 boys; mean age $12.31 \pm 4.06$ years) treated with GCS and corticosteroid-sparing agents: cyclosporin (CsA), mycophenolate mofetil (MMF), and azathioprine (AZA). The distribution of administered immunosuppressive drugs in this subgroup was as follows: 17 children-CsA + GCS, 2 children-MMF + GCS, 2 children-CsA + AZA + GCS, 1 child-CsA + MMF + GCS.

The control group consisted of 18 healthy children (12 girls, 6 boys; mean age $8.40 \pm 3.87$ years), diagnosed for primary nocturnal enuresis or suspected urinary tract abnormalities, which were finally excluded.

Blood and urine were collected once in the control group and twice in the children with INS: at disease onset and immediately after remission was achieved. Blood samples were drawn from cubital vein after an overnight fast, during routinely performed laboratory tests. Samples were clotted for $30 \mathrm{~min}$ and then centrifuged at room temperature for $15 \mathrm{~min}$. Urine samples were collected on the same day as blood samples. After centrifuging them for $15 \mathrm{~min}$, sediment was removed. Biological material was stored frozen at $-70{ }^{\circ} \mathrm{C}$ until assayed. Serum and urine Hpx, serum creatinine, albumin, total cholesterol and CRP (Creactive protein) levels, and urine creatinine and protein concentrations were determined in all children. In all enrolled patients, inflammatory parameters were negative and renal function was normal (creatinine was determined by enzymatic method, the estimated GFR calculated according to the Schwartz formula [36]). Proteinuria was assessed by the urinary protein creatinine ratio (uPCR) on a first morning urine sample. A uPCR $>2(2 \mathrm{mg} / \mathrm{mg})$ was assumed as the value defining nephrotic proteinuria [2]. Other biochemical tests were determined by standard laboratory methods using an Olympus 5800 analyzer.

Hemopexin concentrations in serum ( $\mathrm{sHpx}$ ) and urine $(\mathrm{uHpx})$ were determined by ELISA using commercial assays according to the manufacturer's instructions (AssayPro, St. Charles, MO, USA, kit catalog number for serum assays: EH1001-1, for urine assays: EH2001-1). The evaluations were performed twice and then the average of obtained results was calculated. Hpx values were expressed in $\mathrm{ng} / \mathrm{mL}$. The sensitivity of the method was $50 \mathrm{ng} / \mathrm{mL}$ and $4 \mathrm{ng} / \mathrm{mL}$ for sHpx and $\mathrm{uHpx}$, respectively.

Kidney biopsy was performed in 18 children with INS with frequent relapses: MCD was diagnosed in 3 children, FSGS in 7 , and MGN in 8 . In the remaining patients with a good therapeutic response to GCS, MCD was diagnosed empirically, which is in line with the current recommendations. Histopathological examinations of kidney biopsies were carried out and assessed at the Department of Patho-morphology and Oncological Cytology of the Medical University in Wroclaw. Histopathological analysis included light microscopy, histochemical and immunohistochemical examinations.

The study was conducted according to the guidelines of the Declaration of Helsinki, and approved by the Bioethics Committee of the Wroclaw Medical University (No. KB199/2009). Informed consent was obtained from the parents and subjects above 16 years old.

\section{Statistical Analysis}

The results are expressed as median values and interquartile ranges. Due to the small number of patients, verification of the hypothesis of median value equality in regard to studied parameters in individual groups was carried out using the non-parametric Kruskal-Wallis rank sum test. Verification of the hypothesis of median value equality in regard to the studied parameters in individual dependent samples (e.g., relapse-remission) 
was conducted using non-parametric Wilcoxon pair sequence test. Relations between parameters were defined by Pearson's correlation coefficient $\mathrm{r}$. A $p$ value $<0.05$ was considered statistically significant. The statistical analysis was performed using a software package EPIINFO Ver. 7.1.1.14 Centers for Disease Control and Prevention (CDC), Atlanta, GA, USA (dated 2 July 2013). The results are presented in the tables and figure.

\section{Results}

All examined parameters in controls were within the normal range.

The data of basic biochemical parameters in children with INS are shown in the table below (Table 1). A significantly higher level of proteinuria during relapse was shown in children requiring additional immunosuppressive treatment compared to the group treated only with GCS.

Table 1. Selected biochemical parameters in all children with INS and in examined subgroups according to the number of relapses and treatment modality. Data are presented as median values and interquartile ranges.

\begin{tabular}{ccccc}
\hline $\begin{array}{c}\text { Parameter } \\
\text { Group }\end{array}$ & $\begin{array}{c}\text { Serum Albumin } \\
\text { [g/dL] }\end{array}$ & $\begin{array}{c}\text { Total } \\
\text { Cholesterol } \\
\text { [mg/dL] }\end{array}$ & $\begin{array}{c}\text { Protein/Creatinine } \\
\text { Ratio } \\
\text { [g Protein/g } \\
\text { Creatinine] }\end{array}$ & $\begin{array}{c}\text { CRP } \\
\text { [mg/L] }\end{array}$ \\
\hline Total INS & 1.90 & 363.0 & 6.2 & 2.90 \\
$N=51$ & $(1.05-2.55)$ & $(268.0-475.0)$ & $(3.0-10.6)$ & $(0.80-3.60)$ \\
\hline Group IA & 1.70 & 372.0 & 4.85 & 1.75 \\
$N=20$ & $(1.40-2.20)$ & $(297.0-464.0)$ & $(2.40-7.90)$ & $(0.40-3.60)$ \\
\hline Group IB & 2.40 & 329.5 & 7.0 & 3.10 \\
$N=31$ & $(1.00-3.10)$ & $(238.0-601.0)$ & $(3.9-10.7)$ & $(1.65-3.69)$ \\
\hline Group IIA & 1.90 & 366.5 & 4.71 & 3.30 \\
$N=26$ & $(1.10-2.50)$ & $(286.5-442.5)$ & $(2.5-7.76)$ & $(1.40-3.60)$ \\
\hline Group IIB & 2.0 & 329.5 & 9.6 & 2.56 \\
$N=22$ & $(1.00-2.50)$ & $(264.0-636.0)$ & $(6.2-19.2)$ & $(1.60-4.20)$ \\
\hline
\end{tabular}

a_group IIA versus group IIB, $p=0.023$, Kruskal-Wallis test. INS, idiopathic nephrotic syndrome; CRP, Creactive protein; Group IA- children with the first occurrence of INS; Group IB- children with relapses of INS, Group IIA- children treated only with GCS, gluco-corticosteroids; Group IIB- children treated with GCS and corticosteroid-sparing agents.

sHpx and uHpx levels in the whole INS group were significantly higher, both in relapse and remission, compared to the controls. Additionally, sHpx and uHpx values in relapse were increased compared to those in remission (Table 2, Figure 1).

Table 2. Serum and urine Hpx levels in the whole group of INS children, depending on disease clinical phase compared to the control group. Data are presented as median values and interquartile ranges.

\begin{tabular}{|c|c|c|c|}
\hline $\begin{array}{c}\text { Group } \\
\text { Parameter }\end{array}$ & Relapse & Remission & Control \\
\hline $\begin{array}{c}\mathrm{sHpx} \\
{[\mathrm{ng} / \mathrm{mL}]}\end{array}$ & $\begin{array}{c}107.6 \\
(97.2-114.0)^{a, b}\end{array}$ & $\begin{array}{c}51.2 \\
(46.4-55.6)^{a}\end{array}$ & $\begin{array}{c}32.2 \\
(30.8-33.6)\end{array}$ \\
\hline $\begin{array}{c}\mathrm{uHpx} \\
{[\mathrm{ng} / \mathrm{mL}]}\end{array}$ & $\begin{array}{c}62.8 \\
(55.3-128.0)^{a, b}\end{array}$ & $\begin{array}{c}27.5 \\
(22.9-31.1)^{a}\end{array}$ & $\begin{array}{c}15.8 \\
(14.4-17.5)\end{array}$ \\
\hline
\end{tabular}




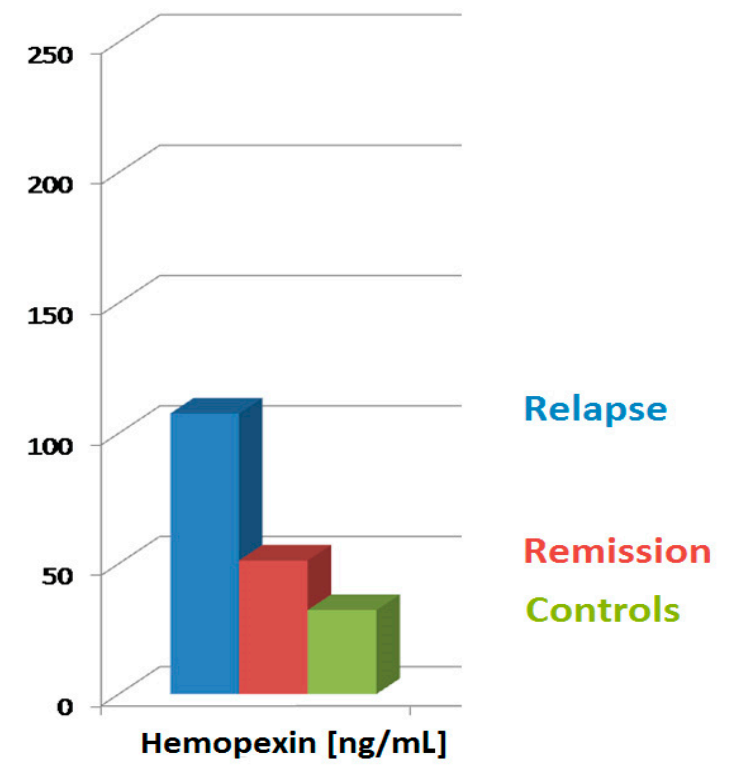

Figure 1. sHpx levels according to clinical phase of the disease, compared to control group. sHpx, serum hemopexin.

Analyzing the group of children with the first manifestation of the disease and the group of children with subsequent relapses, we did not show a significant difference in the concentration of $\mathrm{sHpx}$, both in relapse and in remission. uHpx excretion was comparable in the acute phase of the disease in both groups.

On the other hand, children with the first onset of the disease shortly after reaching remission demonstrated lower $\mathrm{uHpx}$ values than those with subsequent remission (Table 3).

Table 3. sHpx and uHpx levels in INS subgroups according to the number of relapses (group IA-the onset of disease, IB-subsequent relapses). Data are presented as median values and interquartile ranges.

\begin{tabular}{|c|c|c|c|c|}
\hline $\begin{array}{c}\text { Group } \\
\text { Parameter }\end{array}$ & $\begin{array}{c}\text { IA } \\
\text { Relapse } \\
N=20\end{array}$ & $\begin{array}{c}\text { IB } \\
\text { Relapse } \\
N=31\end{array}$ & $\begin{array}{c}\text { IA } \\
\text { Remission } \\
N=9\end{array}$ & $\begin{array}{c}\text { IB } \\
\text { Remission } \\
N=26\end{array}$ \\
\hline $\begin{array}{c}\mathrm{sHpx} \\
{[\mathrm{ng} / \mathrm{mL}]}\end{array}$ & $\begin{array}{c}108.8 \\
(104.0-115.8)\end{array}$ & $\begin{array}{c}105.2 \\
(96.0-114.0)\end{array}$ & $\begin{array}{c}46.4 \\
(42.0-58.0)\end{array}$ & $\begin{array}{c}51.2 \\
(49.2-53.6)\end{array}$ \\
\hline $\begin{array}{c}\mathrm{uHpx} \\
{[\mathrm{ng} / \mathrm{mL}]}\end{array}$ & $\begin{array}{c}61.8 \\
(57.1-148.0)\end{array}$ & $\begin{array}{c}71.4 \\
(55.2-121.4)\end{array}$ & $\begin{array}{c}24.2 \\
(21.7-26.0)^{\mathrm{a}}\end{array}$ & $\begin{array}{c}28.2 \\
(24.8-33.2)\end{array}$ \\
\hline
\end{tabular}

a_group IA versus group IB, $p=0.006$.

There was no difference in sHpx levels between the group receiving only GCS (group IIA) and children receiving GCS and additional immunosuppressants (group IIB), both in the relapse and in the remission. However, there was a difference in uHpx values between these groups. During the relapse uHpx was significantly higher, and then in the remission-lower in children receiving only GCS (Table 4). 
Table 4. sHpx and uHpx levels in the patient groups according to the treatment modality (group IIA-only GCS, IIB-GCS with immunosuppressive sparing agents). Data are presented as median values and interquartile ranges.

\begin{tabular}{|c|c|c|c|c|}
\hline $\begin{array}{c}\text { Group } \\
\text { Parameter }\end{array}$ & $\begin{array}{c}\text { IIA } \\
\text { Relapse } \\
N=26\end{array}$ & $\begin{array}{c}\text { IIB } \\
\text { Relapse } \\
N=22\end{array}$ & $\begin{array}{c}\text { IIA } \\
\text { Remission } \\
N=17\end{array}$ & $\begin{array}{c}\text { IIB } \\
\text { Remission } \\
N=17\end{array}$ \\
\hline $\begin{array}{c}\mathrm{sHpx} \\
{[\mathrm{ng} / \mathrm{mL}]}\end{array}$ & $\begin{array}{c}108.2 \\
(97.2-123.6)\end{array}$ & $\begin{array}{c}103.4 \\
(95.6-108.8)\end{array}$ & $\begin{array}{c}51.2 \\
(42.0-55.6)\end{array}$ & $\begin{array}{c}51.2 \\
(49.2-53.6)\end{array}$ \\
\hline $\begin{array}{c}\mathrm{uHpx} \\
{[\mathrm{ng} / \mathrm{mL}]}\end{array}$ & $\begin{array}{c}103.0 \\
(57.2-158.0)^{\mathrm{a}}\end{array}$ & $\begin{array}{c}61.1 \\
(55.2-81.4)\end{array}$ & $\begin{array}{c}24.8 \\
(22.1-27.5)^{b}\end{array}$ & $\begin{array}{c}31.1 \\
(27.5-35.0)\end{array}$ \\
\hline
\end{tabular}

a_group IIA vs. IIB, $p=0.026{ }^{\text {b }}$-group IIA vs. IIB, $p=0.0017$.

Correlation analysis performed in the whole group of INS children in relapse did not show any relationship between the sHpx and uHpx levels and CRP, albumin, total cholesterol or proteinuria.

The analysis of sHpx and uHpx concentrations in the acute phase of the disease did not show any significant statistical difference between the groups depending on the histopathological diagnosis. However, in remission, a statistically significant lower median concentration of $\mathrm{uHpx}$ was demonstrated in the group of children diagnosed with MCD compared to the group with MGN $(p=0.01)$. However, due to the small number of patients in the analyzed subgroups, the above observations have not been fully presented in our current study.

\section{Discussion}

The involvement of circulating factors in the pathogenesis of nephrotic syndrome in children, not associated with mutation of genes encoding podocyte or basement membrane proteins, has long been discussed [37-39]. Experimental results have suggested that one of these factors may be hemopexin, existing in plasma in an inactive form. The active form of Hpx exhibits serine protease properties and can affect podocyte function and structure [40]. Studies in rats have shown, among other facts, that administration of recombinant Hpx to one kidney results in a reversible, massive proteinuria and morphological changes, similar to those observed in $\mathrm{MCD}$, with a loss of negative charge of the glomerular filtration barrier [41]. Lennon et al. demonstrated that Hpx induces nephrin-dependent reorganization of the cytoskeleton of podocytes by rearranging the actin in their cytoskeleton and reducing the glycocalyx [42]. The authors also found that preincubation of podocytes with plasma from healthy humans significantly reduced the degree of cytoskeletal reorganization after Hpx administration, suggesting that, in patients with MCD lesions, protective plasma factors may be lost, rendering podocytes vulnerable to active Hpx. The aim of our study was to show whether the Hpx levels in serum and urine change in children with INS, which would indirectly indicate their role in the induction of nephrotic proteinuria. In this study, the whole INS group showed significantly increased levels of sHpx and uHpx in the relapse, compared to the control group. In remission, the sHpx and uHpx values decreased, but they were still significantly higher than in healthy children, which may suggest the influence of Hpx on the induction of proteinuria. In our study, we also attempted to measure Hpx in children with nephrotic proteinuria in the course of other glomerulopathies. Our preliminary research showed increased sHpx and uHpx concentrations during the relapse and the remission, and these values were not statistically different from those in the group of children diagnosed with INS (results not published). However, it was a very heterogeneous and small group (10 children) and for this reason, we did not include this group in this study. Despite the fact that our observation is based on a small group of children, it seems interesting in the context of further research on the role of Hpx in the development of proteinuria, not only in INS but also in children with other glomerulopathies.

In the literature, data on this subject are scarce. The results of the only study are not entirely consistent with our observations. Bakker et al., who studied nephrotic syndrome 
due to MCD in children, showed reduced plasma Hpx levels compared to controls [38]. The lowest values were noted in the relapse [43]. These discrepancies are probably due to the use of different methods for Hpx determination and, in addition, the control group was numerically small and differed in age from the study group. The rocket electrophoresis method was used to determine the plasma Hpx titer using anti-Hx IgG. The authors emphasized that plasma titers could be underestimated due to changed Hpx configurations. On the other hand, the control group of 10 subjects consisted of adults up to 35 years of age, whose Hpx titers did not differ from two control samples of children, whose age was not given. It is worth reminding that serum Hpx level changes with age: in neonates this value constitutes about $20 \%$ and in children about $80 \%$ of the adult value (i.e., $0.4-1.5 \mathrm{~g} / \mathrm{L}$ ) [44-46]. The fact that children in remission constituted a different group than those in relapse, as well as a lack of data concerning the time when the samples were taken from the moment of achieving remission, also raises doubts. The methods of statistical analysis were not provided either. Regarding urinary Hpx levels, the authors only report that their values in patients in the relapse were higher than in remission, which is consistent with our results, but lower compared to the controls. However, the lack of data on the statistical significance of the differences does not allow us to interpret the results or to compare them with our results. The authors explain the decrease in plasma Hpx levels in the acute phase of MCD by a possible change in the configuration of the Hpx molecule into an isoform exhibiting protease activity. In fact, they found a marked increase in it by examining the expression of ecto-apyrase, an indicator of glomerular extracellular matrix damage, after prior incubation of kidney sections in plasma from children with nephrotic range proteinuria. In contrast, protease activity was not demonstrated after using plasma from patients with MCD in remission and plasma from healthy subjects. What is the explanation for the increase of Hpx concentration in MCD? Hpx is mainly produced by the liver as an acute phase protein after stimulation with post-inflammatory cytokines, including IL-1 and IL-6, and reflects activation of the inflammatory cascade [47]. In this study no correlation between Hpx and CRP was found, which does not exclude its hepatic synthesis by other inflammatory factors. Indeed, IL-6 levels have been shown to increase in MCD relapse, both in adults and children $[48,49]$.

Hpx can also be partially released into the circulation from glomerular mesangial cells, as evidenced by the observations of Kapajos et al. [50]. Indeed, they demonstrated the presence of Hpx in the supernatant of glomerular mesangial cells collected from healthy individuals after prior incubation with TNF-alpha. It is likely that the local production of Hpx by these cells also acts directly on the glomerular filtration barrier, including podocytes. In our study, the fact that shortly after reaching remission Hpx levels, although lower than in relapse, do not normalize, indicates that pathological processes have not been fully silenced.

This is a premise for the continuation of treatment. From the previously presented experimental studies, it is clear that $\mathrm{Hpx}$ affects the permeability of the glomerular filtration barrier and leads to proteinuria. Therefore, one would expect a relationship between the tested glycoprotein and proteinuria. However, no such correlation was demonstrated. This may be due to the small size of the study group. The relationship between serum Hpx and proteinuria was demonstrated by Krikken et al. in their study of 557 renal transplant recipients at risk of graft loss. They demonstrated significantly higher proteinuria in patients with higher plasma Hpx levels and more rapid dysfunction of the transplanted kidney compared with patients with lower Hpx values. Although multivariate analysis showed that this glycoprotein is also an independent risk factor for kidney allograft loss, according to the authors increased permeability of glomerular filtration barrier to proteins is important; proteinuria is a recognized modifiable factor in the progression of chronic kidney disease [51].

Considering the division of patients according to the number of relapses (first occurrence of INS vs. subsequent relapses of INS, treated with GCS), it was shown that serum Hpx levels in relapse and remission are similar, whereas urinary Hpx levels in remission 
are significantly higher in children with subsequent relapses compared to patients with first episode of INS. To the best of our knowledge, this is the first observation of this kind, probably related to shorter intervals between relapses, which are not sufficient to silence the disorganization of the glomerular filtration barrier. Similar observations were made by Pukajło and Zwolińska, who studied the same groups of children with INS in relation to IL-13-a circulating factor considered a significant enhancer of glomerular permeability in MCD [52].

Taking into account the division according to a more or less intensive therapy, it was demonstrated that serum Hpx concentration, both in relapse and remission, is similar in both groups, contrary to its urinary values. Urinary Hpx excretion was significantly higher in relapse than in remission in children treated only with GCS. This is also the first observation of this kind. Perhaps, during relapse in the group receiving additional immunosuppressive drugs, it is related to a greater suppression of immunocompetent cells with a subsequent decrease in the production of cytokines involved in the pathogenesis of $\mathrm{MCD}$, according to the "two-hit" theory. In turn, increased uHpx in remission could be explained by the persistence of higher local levels of these cytokines in children receiving combination therapy. This hypothesis is supported, among other factors, by the higher urinary IL-13 levels in this group of patients during remission; however, it should be emphasized that they are significantly lower in relation to the values in relapse [52].

Correlation studies on Hpx and biochemical markers of nephrotic syndrome did not show significant associations in the whole group of patients.

As mentioned above, the expected correlation between proteinuria and Hpx was not found in any of the study groups. The explanation of this fact may be, apart from the small number of patients, the influence of other circulating factors, including cytokines, which interact leading to one goal. The link between Hpx and the cytokine network is supported by the results of numerous studies, concerning inflammatory processes, including sepsis [53,54], as well as the aforementioned observations presented by Kapajos et al. [45].

This study has several limitations. Firstly, it is a single center study and the group size is limited. We are aware that the number of children in the control group is relatively small. However, it should be noted that small differences in values of Hpx, both in the serum and urine, between the healthy subjects were shown. Secondly, the subgroup receiving combination therapy is rather heterogenic. However, pediatric nephrologists are familiar with the difficulty of selecting a homogeneous group among children with steroid-dependent and frequent-relapsing INS, requiring alternative treatment. Third, our study is a retrospective study. A long-term prospective study would be necessary to confirm our suggestion concerning the role of $\mathrm{Hpx}$ as a disease predictor. It would be very valuable to compare the dynamics of Hpx concentrations at the first onset of the disease and at each subsequent relapse in a single patient, and then to analyze the results in groups depending on the number of relapses. We hope that our current results will encourage the programming of further research in this area.

\section{Conclusions}

The increased sHpx and uHpx levels in relapse of INS, as well as their significant decrease in remission, suggest the role of this circulating factor in the pathogenesis of nephrotic range proteinuria. Maintenance of elevated sHpx and uHpx values just after reaching remission speak to the persistence of immune system activation and the need for further treatment. Increased uHpx concentration in children with subsequent relapses, when compared to patients with the first INS episode, may be a useful prognostic marker of the course of INS and an indicator for continuation of immunosuppressive treatment.

Further prospective studies are needed to confirm our results and to concern Hpx as a target for alternative therapy. We are aware that the pathogenesis of INS is complex and that new factors involved in this process are constantly being sought. Our work is part of the research on new pathogenetic links that may enrich therapeutic solutions in the future. 
Author Contributions: A.P.-M.: conception, study design, collection and interpretation of data, and manuscript writing; D.Z.: conception, interpretation of data, revision of the manuscript. All authors have read and agreed to the published version of the manuscript.

Funding: This work was financed by a grant from the Wroclaw Medical University, Poland (grant number: Pbmn35).

Institutional Review Board Statement: Not applicable.

Informed Consent Statement: Informed consent was obtained from all subjects ( $\geq 16$ years) and their representatives involved in the study.

Data Availability Statement: Not applicable.

Conflicts of Interest: All the authors declared no conflict of interest.

\section{References}

1. Lipska-Ziętkiewicz, B.S.; Ozaltin, F.; Hölttä, T.; Bockenhauer, D.; Bérody, S.; Levtchenko, E.; Vivarelli, M.; Webb, H.; Haffner, D.; Schaefer, F.; et al. Genetic aspects of congenital nephrotic syndrome: A consensus statement from the ERKNet-ESPN inherited glomerulopathy working group. Eur. J. Hum. Genet. 2020, 28, 1368-1378. [CrossRef]

2. Giliberti, M.; Mitrotti, A.; Gesualdo, L. Podocytes: The Role of Lysosomes in the Development of Nephrotic Syndrome. Am. J. Pathol. 2020, 190, 1172-1174. [CrossRef]

3. Shima, Y.; Nakanishi, K.; Sato, M.; Hama, T.; Mukaiyama, H.; Togawa, H.; Tanaka, R.; Nozu, K.; Sako, M.; Iijima, K.; et al. IgA nephropathy with presentation of nephrotic syndrome at onset in children. Pediatr. Nephrol. 2016, 32, 457-465. [CrossRef]

4. Peruzzi, L.; Coppo, R. IgA vasculitis nephritis in children and adults: One or different entities? Pediatr. Nephrol. 2020, 20. [CrossRef]

5. Pinheiro, S.V.B.; Dias, R.; Fabiano, R.C.G.; Araujo, S.D.A.; e Silva, A.C.S. Pediatric lupus nephritis. Braz. J. Nephrol. 2019, 41, 252-265. [CrossRef]

6. Nephrotic syndrome in children: Prediction of histopathology from clinical and laboratory characteristics at time of diagnosis. A report of the International Study of Kidney Disease in Children. Available online: https:/ / pubmed.ncbi.nlm.nih.gov/713276/ (accessed on 30 May 2021).

7. KDIGO Clinical Practice Guideline for Glomerulonephritis. Available online: https://kdigo.org/wp-content/uploads/2017/02/ KDIGO-2012-GN-Guideline-English.pdf (accessed on 30 May 2021).

8. Lombel, R.M.; Gipson, D.; Hodson, E.M. Treatment of steroid-sensitive nephrotic syndrome: New guidelines from KDIGO. Pediatr. Nephrol. 2013, 28, 415-426. [CrossRef] [PubMed]

9. Mendonça, A.C.Q.; Oliveira, E.A.; Fróes, B.P.; Faria, L.D.C.; Pinto, J.S.; Nogueira, M.M.I.; Lima, G.O.; Resende, P.I.; Assis, N.S.; e Silva, A.C.S.; et al. A predictive model of progressive chronic kidney disease in idiopathic nephrotic syndrome. Pediatr. Nephrol. 2015, 30, 2011-2020. [CrossRef] [PubMed]

10. Chen, J.; Qiao, X.-H.; Mao, J.-H. Immunopathogenesis of idiopathic nephrotic syndrome in children: Two sides of the coin. World J. Pediatr. 2021, 17, 115-122. [CrossRef] [PubMed]

11. Shalhoub, R. PATHOGENESIS OF LIPOID NEPHROSIS: A DISORDER OF T-CELL FUNCTION. Lancet 1974, 304, 556-560. [CrossRef]

12. Garin, E.H.; West, L.; Zheng, W. Effect of interleukin-8 on glomerular sulfated compounds and albuminuria. Pediatr. Nephrol. 1997, 11, 274-279. [CrossRef] [PubMed]

13. Souto, M.F.O.; Teixeira, A.L.; Russo, R.C.; Penido, M.-G.M.G.; Silveira, K.D.; Teixeira, M.M.; e Silva, A.C.S. Immune Mediators in Idiopathic Nephrotic Syndrome: Evidence for a Relation Between Interleukin 8 and Proteinuria. Pediatr. Res. 2008, 64, 637-642. [CrossRef] [PubMed]

14. Lai, K.-W.; Wei, C.-L.; Tan, L.-K.; Tan, P.-H.; Chiang, G.S.; Lee, C.; Jordan, S.C.; Yap, H.K. Overexpression of Interleukin-13 Induces Minimal-Change-Like Nephropathy in Rats. J. Am. Soc. Nephrol. 2007, 18, 1476-1485. [CrossRef]

15. Reiser, J.; Mundel, P. Danger signaling by glomerular podocytes defines a novel function of inducible B7-1 in the pathogenesis of nephrotic syndrome. J. Am. Soc. Nephrol. 2004, 15, 2246-2248. [CrossRef]

16. Shimada, M.; Araya, C.; Rivard, C.; Ishimoto, T.; Johnson, R.J.; Garin, E.H. Minimal change disease: A “two-hit" podocyte immune disorder? Pediatr. Nephrol. 2011, 26, 645-649. [CrossRef] [PubMed]

17. Cara-Fuentes, G.; Wasserfall, C.H.; Wang, H.; Johnson, R.J.; Garin, E.H. Minimal change disease: A dysregulation of the podocyte CD80-CTLA-4 axis? Pediatr. Nephrol. 2014, 29, 2333-2340. [CrossRef]

18. Kim, J.E.; Park, S.J.; Ha, T.S.; Shin, J.I. Effect of rituximab in MCNS: A role for IL-13 suppression? Nat. Rev. Nephrol. 2013, 9, 551. [CrossRef] [PubMed]

19. Davin, J.-C. The glomerular permeability factors in idiopathic nephrotic syndrome. Pediatr. Nephrol. 2015, 31, 207-215. [CrossRef]

20. Wei, C.; Trachtman, H.; Li, J.; Dong, C.; Friedman, A.L.; Gassman, J.J.; McMahan, J.L.; Radeva, M.; Heil, K.M.; Trautmann, A.; et al. PodoNet and FSGS CT Study Consortia. Circulating suPAR in Two Cohorts of Primary FSGS. J. Am. Soc. Nephrol. 2012, 23, 2051-2059. [CrossRef] 
21. Li, F.; Zheng, C.; Zhong, Y.; Zeng, C.; Xu, F.; Yin, R.; Jiang, Q.; Zhou, M.; Liu, Z.-H. Relationship between Serum Soluble Urokinase Plasminogen Activator Receptor Level and Steroid Responsiveness in FSGS. Clin. J. Am. Soc. Nephrol. 2014, 9, $1903-1911$. [CrossRef]

22. Wada, T.; Nangaku, M. A circulating permeability factor in focal segmental glomerulosclerosis: The hunt continues. Clin. Kidney J. 2015, 8, 708-715. [CrossRef]

23. Cara-Fuentes, G.; Wei, C.; Segarra, A.; Ishimoto, T.; Rivard, C.; Johnson, R.J.; Reiser, J.; Garin, E.H. CD80 and suPAR in patients with minimal change disease and focal segmental glomerulosclerosis: Diagnostic and pathogenic significance. Pediatr. Nephrol. 2014, 29, 1363-1371. [CrossRef]

24. Muller-Eberhard, U. Hemopexin. Methods Enzymol. 1998, 163, 536-568. [CrossRef] [PubMed]

25. Naylor, S.L.; Altruda, F.; Marshall, A.; Silengo, L.; Bowman, B.H. Hemopexin is localized to human chromosome 11. Somat. Cell Mol. Genet. 1987, 13, 355-358. [CrossRef] [PubMed]

26. Altruda, F.; Poli, V.; Restagno, G.; Silengo, L. Structure of the human hemopexin gene and evidence for intron-mediated evolution. J. Mol. Evol. 1988, 27, 102-108. [CrossRef] [PubMed]

27. Takahasi, N.; Takahashi, Y.; Putnam, F.W. Complete aminoacid sequence of human hemopexin, the heme-binding protein of serum. Proc. Natl. Acid. Sci. USA 1985, 82, 73-77. [CrossRef] [PubMed]

28. Smith, A. Role of Redox-Reactive Metals in the Regulation of Metallothionein and Hemeoxygenase Genes by Heme and Hemopexin. In Iron Metabolism; Ferreira, G.C., Moura, J.J.G., Franco, R., Eds.; Wiley-VCH: Weinheim, Germany, 1999; pp. 65-92.

29. Delanghe, J.R.; Langlois, M.R. Hemopexin: A review of biological aspects and the role in laboratory medicine. Clin. Chim. Acta 2001, 312, 13-23. [CrossRef]

30. Bernard, A.; Amor, A.O.; Goemare-Vanneste, J.; Antoine, J.-L.; Lauwerys, R.; Colin, I.; Vandeleene, B.; Lambert, A. Urinary proteins and red blood cell membrane negative charges in diabetes mellitus. Clin. Chim. Acta 1990, 190, 249-262. [CrossRef]

31. Chen, C.-C.; Lu, Y.-C.; Chen, Y.-W.; Lee, W.-L.; Lu, C.-H.; Chen, Y.-H.; Lee, Y.-C.; Lin, S.-T.; Timms, J.; Lee, Y.-R.; et al. Hemopexin is up-regulated in plasma from type 1 diabetes mellitus patients: Role of glucose-induced ROS. J. Proteom. 2012, 75, 3760-3777. [CrossRef]

32. Maes, M.; Delange, J.; Ranjan, R.; Meltzer, H.Y.; Desnyder, R.; Cooremans, W.; Scharpé, S. Acute phase proteins in schizophrenia, mania and major depression: Modulation by psychotropic drugs. Psychiatry Res. 1997, 66, 1-11. [CrossRef]

33. Manuel, Y.; Defontaine, M.; Bourgoin, J.; Dargent, M.; Sonneck, J. Serum haemopexin levels in patients with malignant melanoma. Clin. Chim. Acta 1971, 31, 485-486. [CrossRef]

34. Percy, M.E.; Pichora, G.A.; Chang, L.S.; Manchester, K.E.; Andrews, D.F.; Opitz, J.M. Serum myoglobin in Duchenne muscular dystrophy carrier detection: A comparison with creatine kinase and hemopexin using logistic discrimination. Am. J. Med. Genet. 1984, 18, 279-287. [CrossRef]

35. International Study of Kidney Disease in Children. Primary nephrotic syndrome in children: Clinical significance of histopathologic variants of minimal change and of diffuse mesangial hypercellularity. A Report of the International Study of Kidney Disease in Children. Kidney Int. 1981, 20, 765-771. [CrossRef]

36. Schwartz, G.J.; Muñoz, A.; Schneider, M.F.; Mak, R.H.; Kaskel, F.; Warady, B.A.; Furth, S.L. New Equations to Estimate GFR in Children with CKD. J. Am. Soc. Nephrol. 2009, 20, 629-637. [CrossRef] [PubMed]

37. Cheung, P.K.; Boes, A.; Dijkhuis, F.W.J.; Klok, P.A.; Bakker, W.W. Enhanced glomerular permeability andminimal change disease like alterations of the rat kidney indced by a vasoactive human plasma factor. Kidney Int. 1995, 47, 1218.

38. Cheung, P.K.; Klok, P.A.; Bakker, W.W. Induction of experimental proteinuria in vivo following infusion of a human stain factor associated with minimal change disease. Kidney Int. 1997, 52, 562.

39. Cheung, P.K.; Klok, P.A.; Bakker, W.W. Minimal change-like glomerular alterations induced by a human plasma factor. Nephron 1996, 74, 586-593. [CrossRef]

40. Cheung, P.K.; Stulp, B.; Immenschuh, S.; Borghuis, T.; Baller, J.F.W.; Bakker, W.W. Is 100KF an Isoform of Hemopexin? Immunochemical Characterization of the Vasoactive Plasma Factor 100KF. J. Am. Soc. Nephrol. 1999, 10, 1700-1708. [CrossRef] [PubMed]

41. Bakker, W.W.; Borghuis, T.; Harmsen, M.; Berg, A.V.D.; Kema, I.P.; Niezen, K.E.; Kapojos, J.J. Protease activity of plasma hemopexin. Kidney Int. 2005, 68, 603-610. [CrossRef]

42. Lennon, R.; Singh, A.; Welsh, G.I.; Coward, R.; Satchell, S.; Ni, L.; Mathieson, P.W.; Bakker, W.W.; Saleem, M.A. Hemopexin Induces Nephrin-Dependent Reorganization of the Actin Cytoskeleton in Podocytes. J. Am. Soc. Nephrol. 2008, 19, $2140-2149$. [CrossRef] [PubMed]

43. Bakker, W.W.; Van Dael, C.M.L.; Pierik, L.J.W.M.; Van Wijk, J.A.E.; Nauta, J.; Borghuis, T.; Kapojos, J.J. Altered activity of plasma hemopexin in patients with minimal change disease in relapse. Pediatr. Nephrol. 2005, 20, 1410-1415. [CrossRef]

44. Thomas, L. Haptoglobin/Hemopexin. In Clinical Laboratory Diagnostics; Thomas, L., Ed.; TH-Books: Frankfurt/Main, Germany, 1998; pp. 663-667.

45. Kanakoudi, F.; Drossou, V.; Tzimouli, V.; Diamanti, E.; Konstantinidis, T.; Germenis, A.; Kremenopoulos, G. Serum concentrations of 10 acute-phase proteins in healthy term and preterm infants from birth to age 6 months. Clin. Chem. 1995, 41, 605-608. [CrossRef]

46. Weeke, B.; Krasilnikoff, P.A. The concentration of 21 serum proteins in normal children and adults. Acta Med. Scand. 2009, 192, 149-155. [CrossRef] 
47. Tolosano, E.; Altruda, F. Hemopexin: Structure, Function, and Regulation. DNA Cell Biol. 2002, 21, 297-306. [CrossRef] [PubMed]

48. Oniszczuk, J.; Beldi-Ferchiou, A.; Audureau, E.; Azzaoui, I.; Molinier-Frenkel, V.; Frontera, V.; Karras, A.; Moktefi, A.; Pillebout, E.; Zaidan, M.; et al. Circulating plasmablasts and high level of BAFF are hallmarks of minimal change nephrotic syndrome in adults. Nephrol. Dial. Transplant. 2021, 36, 609-617. [CrossRef]

49. Nickavar, A.; Valavi, E.; Safaeian, B.; Amoori, P.; Moosavian, M. Predictive Value of Serum Interleukins in Children with Idiopathic Nephrotic Syndrome. Iran. J. Allergy Asthma Immunol. 2020, 19, 632-639. [CrossRef]

50. Kapojos, J.J.; Berg, A.V.D.; van Goor, H.; Loo, M.W.T.; Poelstra, K.; Borghuis, T.; Bakker, W.W. Production of hemopexin by TNF- $\alpha$ stimulated human mesangial cells. Kidney Int. 2003, 63, 1681-1686. [CrossRef] [PubMed]

51. Krikken, J.A.; Van Ree, R.M.; Klooster, A.; Seelen, M.A.; Borghuis, T.; Lems, S.P.M.; Schouten, J.P.; Bakker, W.W.; Gans, R.; Navis, G.; et al. High plasma hemopexin activity is an independent risk factor for late graft failure in renal transplant recipients. Transpl. Int. 2010, 23, 805-812. [CrossRef] [PubMed]

52. Pukajło-Marczyk, A.; Zwolińska, D. The role of IL-13 in the pathogenesis of idiopathic nephrotic syndrome (INS) in children. Fam. Med. Prim. Care Rev. 2016, 2, 149-154. [CrossRef]

53. Liang, X.; Lin, T.; Sun, G.; Beasley-Topliffe, L.; Cavaillon, J.-M.; Warren, H.S. Hemopexin down-regulates LPS-induced proinflammatory cytokines from macrophages. J. Leukoc. Biol. 2009, 86, 229-235. [CrossRef] [PubMed]

54. Lin, T.; Kwak, Y.H.; Sammy, F.; He, P.; Thundivalappil, S.; Sun, G.; Chao, W.; Warren, H.S. Synergistic Inflammation Is Induced by Blood Degradation Products with Microbial Toll-Like Receptor Agonists and Is Blocked by Hemopexin. J. Infect. Dis. 2010, 202, 624-632. [CrossRef] 